\title{
Multi-Objective Quadratic Programming Problem: A Priority based Fuzzy Goal Programming
}

\author{
Surapati Pramanik \\ Department of Mathematics, Nandalal Ghosh \\ B.T. College, Panpur, P.O.- Narayanpur, District \\ - North 24 Parganas, Pin code-743126, West \\ Bengal, India
}

\author{
Partha Pratim Dey \\ Patipukur Pallisree Vidyapith, 1, Pallisree \\ Colony, Patipukur, Kolkata-700048, West \\ Bengal, India
}

\begin{abstract}
This paper presents priority based fuzzy goal programming approach to multi-objective quadratic programming problem. In the proposed approach, we construct the quadratic membership functions by determining the individual best solution of the objective functions subject to the system constraints. The quadratic membership functions are then transformed into equivalent linear membership functions at the individual best solution point by first order Taylor series approximation. Then fuzzy goal programming approach is used for achieving highest degree of each of the membership goals by minimizing negative deviational variables. Then, sensitivity analysis with the variations of the priority structure is performed to identify the most appropriate priority structure in the decision-making context by using distance function. A numerical example is solved in order to show the efficiency of the proposed approach.
\end{abstract}

\section{General Terms}

Multi-objective quadratic programming.

\section{Keywords}

Goal programming, Multi-objective quadratic programming, Priority based fuzzy goal programming, Quadratic programming.

\section{INTRODUCTION}

In the present paper, we have considered priority based fuzzy goal programming (FGP) approach for solving multi-objective quadratic programming problem (MOQPP). MOQPP consists of a decision-making unit (DMU) with multiple objectives. Here, the objective functions are quadratic in nature and the system constraints are linear functions.

Our main results are as follows: (i) a priority based FGP approach to MOQPP is presented. (ii) We transform the quadratic membership functions into an equivalent linear membership functions by first order Taylor series approximation at the individual best solution point and priority based FGP is used to solve the transformed MOQPP. (iii) Sensitivity analysis with the variations of the priority structure is performed and distance function is used to identify the most appropriate priority structure in the decision-making context.

It is well known that the priority based goal programming (GP) is one of the powerful techniques in field of multi criteria decision-making problems with multiple and conflicting objectives. Ijiri [1] introduced priority based GP at first in 1965.
Ignizio [2], Lee [3], Steuer [4] and other researchers developed priority based GP and they successfully applied GP to various real-life decision-making problems. In the proposed priority based GP, the ranking of goals are grouped according their priorities for achieving the respective aspiration levels in the decision-making context. The goals, which are considered equal importance, belong to the same priority level. The goals at the first priority level are considered to be infinitely more important than the goals at the second priority level. The goals at the second priority level are considered to be infinitely more important than the goals at the third priority level and so on. Since the goals are generally conflicting in nature, differential weights are assigned to their relative importance for achieving the respective desired values.

MOQPP is a special case of nonlinear programming problem. However, MOQPP has not been studied extensively in the literature. Korhonen and $\mathrm{Yu}$ [5] discussed a reference direction approach to multiple objective quadratic - linear programming problems. Ammar and Khalifa [6] studied quadratic programming to fuzzy portfolio optimization problems. Ammar [7] presented fuzzy random multiobjective quadratic programming with applications in portfolio problem.

In this paper, we have transformed MOQPP into multi-objective linear programming problem by first order Taylor series approximation. Then, FGP approach due to Pramanik and Roy $[8,9]$ is used for achieving highest degree of each of membership goals by minimizing negative deviational variables.

In the priority based FGP solution approach, the goals at the first priority level are considered first for achievement of their aspiration levels according to their relative importance of the weights at that priority level. Then, the achievement of goals of second priority level is taken into consideration and the process will continue until the last priority level is considered.

In the solution process, sensitivity analysis with the variations of priority structure of the goals is performed to identify the most appropriate priority structure by using distance function.

Rest of the paper is organized as follows: section 2 presents the formulation of MOQPP. Section 3 provides fuzzy programming formulation to MOQPP. Subsection 3.1 explains linearization of membership functions by first order Taylor series approximation. Subsection 3.2 describes the priority based FGP approach to MOQPP. Section 4 discusses the selection of appropriate priority structure based on distance function. In section 5, we present priority based FGP algorithm for solving 
MOQPP. In section 6, numerical example is illustrated to show the efficiency of the proposed approach. Section 7 provides the conclusion.

\section{FORMULATION OF MOQPP}

The general formulation of MOQPP can be written as:

$\max Z_{t}(\bar{x})=\bar{C}_{t} \bar{x}+\frac{1}{2}-\bar{x} \bar{D}_{t} \bar{x}(t=1,2, \ldots, k)$

subject to

$$
\overline{\mathrm{x}} \in \mathrm{S}=\left\{\begin{array}{l}
\overline{\mathrm{x}} \in \overline{\mathrm{R}}^{\mathrm{N}} \mid \overline{\mathrm{A}} \overline{\mathrm{x}}\left(\begin{array}{l}
\leq \\
\bar{z} \\
\geq
\end{array}\right) \overline{\mathrm{B}}, \overline{\mathrm{x}} \geq \overline{0}
\end{array}\right\}
$$

Here, $\overline{\mathrm{C}}_{\mathrm{t}}(\mathrm{t}=1,2, \ldots, \mathrm{k})$ and $\overline{\mathrm{B}}$ are constant vectors. $\overline{\mathrm{A}}$ is constant matrix. $\overline{\mathrm{D}}_{\mathrm{t}}(\mathrm{t}=1,2, \ldots, \mathrm{k})$ is constant symmetric matrix. The symbol ' $\mathrm{T}$ ' denotes transposition and $\mathrm{M}$ is the total number of constraints of the system. We assume that the objective functions are concave and the system constraints are convex. Here, we also assume $\mathrm{S}$ to be non-empty and bounded.

\section{FUZZY \\ PROGRAMMING \\ FORMULATION OF MOQPP}

To formulate the fuzzy programming model of MOQPP, the objective functions would be transformed into fuzzy goals by means of assigning an imprecise aspiration level to each of the objectives. The optimal solution of each objective function of the DMU when calculated in isolation would be considered as the best solution and the associated objective value can be considered as the aspiration level of the corresponding fuzzy goal.

Let, $\mathrm{x}_{\mathrm{t}}=\left(\mathrm{x}_{\mathrm{t} 1}^{\mathrm{B}}, \mathrm{x}_{\mathrm{t} 2}^{\mathrm{B}}, \ldots, \mathrm{x}_{\mathrm{tN}}^{\mathrm{B}}\right)(\mathrm{t}=1,2, \ldots, \mathrm{k})$ be the individual best solution of the $t$-th objective function subject to the system constraints.

Also let, $Z_{t}^{B}=Z_{t}\left(\begin{array}{l}-B \\ x_{t}\end{array}\right)=\max _{\bar{x} \in S} Z_{t}(\bar{x})(t=1,2, \ldots, k)$.

It is quite natural that objective values which are equal to or larger than $\mathrm{Z}_{\mathrm{t}}^{\mathrm{B}}(\overline{\mathrm{x}})(\mathrm{t}=1,2, \quad \ldots, \mathrm{k})$ should be absolutely acceptable to the DMU.

Then the fuzzy goals appear in the form:

$\mathrm{Z}_{\mathrm{t}}(\overline{\mathrm{x}}) \geq \mathrm{Z}_{\mathrm{t}}^{\mathrm{B}}(\mathrm{t}=1,2, \ldots, \mathrm{k})$.

To build the membership functions, upper tolerance limit and lower tolerance limit should be determined first. Using the individual best solutions, we find the value of all the objective functions at each best solution and construct a payoff matrix as:

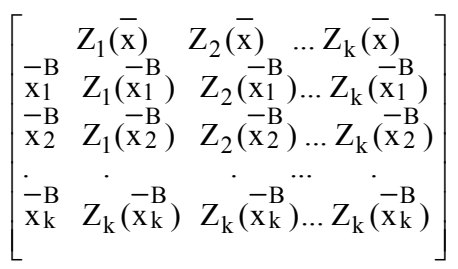

The maximum value of each column of $Z_{t}(\bar{x})(t=1,2, \ldots, k)$ provides the upper tolerance limit or aspired level of achievement for the objective goal. The minimum value of each column provides lower tolerance limit or lowest acceptable level of achievement for the objective goal.

The membership function of the $\mathrm{t}$-th objective function can be defined as:

$\mu_{t}(\bar{x})=\left\{\begin{array}{lc}1, & \text { if } Z_{t}(\bar{x}) \geq Z_{t}^{B} \\ \frac{Z_{t}(\bar{x})-Z_{t}^{W}}{Z_{t}^{B}-Z_{t}^{W}}, & \text { if } Z_{t}^{W} \leq Z_{t}(\bar{x}) \leq Z_{t}^{B} \\ 0, & \text { if } Z_{t}(\bar{x}) \leq Z_{t}^{W}\end{array}\right\} \quad(t=1,2, \ldots, k)$

Here, $Z_{t}^{B}$ and $Z_{t}^{W}$ are respectively the upper and lower tolerance limit of the $\mathrm{t}$-th fuzzy objective goal.

\subsection{Linearization of membership functions by first order Taylor series approximation}

Let, ${ }^{*}{ }^{*}=\left(x_{t 1}^{*}, x_{t 2}^{*}, \ldots, x_{t N}^{*}\right)$ be the individual best solution of $\mu_{t}(\bar{x})(t=1,2, \ldots, k)$ subject to the system constraints, $N$ is the total number of variables. Next, we transform the quadratic membership function $\mu_{\mathrm{t}}(\overline{\mathrm{x}})(\mathrm{t}=1, \quad 2, \quad \ldots, \quad \mathrm{k})$ at $\bar{x}_{\mathrm{t}}^{*}=\left(\mathrm{x}_{\mathrm{t} 1}^{*}, \mathrm{x}_{\mathrm{t} 2}^{*}, \ldots, \mathrm{x}_{\mathrm{tN}}^{*}\right)$ into equivalent linear membership function $\hat{\mu}_{t}(\bar{x})$ by first order Taylor series approximation. The transformed linear membership function can be formulated as:

$$
\begin{aligned}
& \mu_{\mathrm{t}}(\overline{\mathrm{x}}) \cong \mu_{\mathrm{t}}\left(\overline{\mathrm{x}}_{\mathrm{t}}^{*}\right)+\left(\mathrm{x}_{1}-\mathrm{x}_{\mathrm{t} 1}^{*}\right) \frac{\partial \mu_{\mathrm{t}}\left(\mathrm{x}_{\mathrm{t}}^{*}\right)}{\partial \mathrm{x}_{1}}+\left(\mathrm{x}_{2}-\mathrm{x}_{\mathrm{t} 2}^{*}\right) \frac{\partial \mu_{\mathrm{t}}\left(\mathrm{x}_{\mathrm{t}}^{*}\right)}{\partial \mathrm{x}_{2}} \\
& \left.+\ldots+\left(\mathrm{x}_{\mathrm{n}}-\mathrm{x}_{\mathrm{tN}}^{*}\right) \frac{\partial \mu_{\mathrm{t}}\left(\mathrm{x}_{\mathrm{t}}^{*}\right)}{\partial \mathrm{x}_{\mathrm{N}}}\right]=\hat{\mu}_{\mathrm{t}}(\overline{\mathrm{x}})(\mathrm{t}=1,2, \ldots, \mathrm{k})
\end{aligned}
$$

\subsection{Priority based FGP model of MOQPP}

The problem discussed in section (2) reduces to the following problem

$\max \hat{\mu}_{\mathrm{t}}(\overline{\mathrm{x}})(\mathrm{t}=1,2, \ldots, \mathrm{k})$ 
Subject to

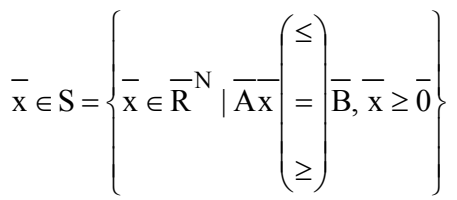

Now, achievement of the highest degree (unity) of a membership function implies absolute achievement of the aspired level of the associated fuzzy goal. So membership goal corresponding to the $\mathrm{t}$-th membership function with unity as the aspiration level can be presented as:

$$
\hat{\mu}_{t}(\bar{x})+d_{t}^{-}-d_{t}^{+}=1(t=1,2, \ldots, k)
$$

Here, $d_{t}^{-}(\geq 0)$ and $d_{t}^{+}(\geq 0)(t=1,2, \ldots, k)$ represent the negative and positive deviational variables respectively. It may be noted that any over deviation from a fuzzy goal indicates the full achievement of the membership value. Then according to Pramanik and Roy $[8,9]$, negative deviational variables are to be minimized in order to get satisfycing solution. Therefore, (7) can be formulated as:

$\hat{\mu}_{t}(\bar{x})+d_{t}^{-} \geq 1 \quad(t=1,2, \ldots, k)$

Therefore, under the framework of min-sum GP, the priority based FGP model of the problem can be explicitly formulated as:

Find $\bar{x}$ so as to

$\operatorname{minimize} \bar{\psi}=\left[\mathrm{P}_{1}\left(\mathrm{~d}^{-}\right), \mathrm{P}_{2}\left(\mathrm{~d}^{-}\right), \ldots, \mathrm{P}_{\mathrm{j}}\left(\mathrm{d}^{-}\right), \ldots, \mathrm{P}_{\mathrm{J}}\left(\mathrm{d}^{-}\right)\right]$

subject to

$$
\begin{aligned}
& \mu_{\mathrm{t}}\left(\overline{\mathrm{x}}_{\mathrm{t}}^{*}\right)+\left[\left(\mathrm{x}_{1}-\mathrm{x}_{\mathrm{t} 1}^{*}\right) \frac{\partial \mu_{\mathrm{t}}\left(\mathrm{x}_{\mathrm{t}}^{*}\right)}{\partial \mathrm{x}_{1}}+\left(\mathrm{x}_{2}-\mathrm{x}_{\mathrm{t} 2}^{*}\right) \frac{\partial \mu_{\mathrm{t}}\left(\mathrm{x}_{\mathrm{t}}^{*}\right)}{\partial \mathrm{x}_{2}}+\ldots+\right. \\
& \left.\left(\mathrm{x}_{\mathrm{N}}-\mathrm{x}_{\mathrm{tN}}^{*}\right) \frac{\partial \mu_{\mathrm{t}}\left(\mathrm{x}_{\mathrm{t}}^{*}\right)}{\partial \mathrm{x}_{\mathrm{N}}}\right]+\mathrm{d}_{\mathrm{t}}^{-} \geq 1,(\mathrm{t}=1,2, \ldots, \mathrm{k}) \\
& \overline{\mathrm{x}} \in \mathrm{S}=\left\{\begin{array}{l}
-\overline{\mathrm{x}} \in \overline{\mathrm{R}}^{\mathrm{N}} \mid \overline{\mathrm{A} x}-\left(\begin{array}{l}
\leq \\
= \\
\geq
\end{array}\right) \overline{\mathrm{B}}, \overline{\mathrm{x}} \geq \overline{0}
\end{array}\right\} \\
& \mathrm{d}_{\mathrm{t}}^{-} \geq 0(\mathrm{t}=1,2, \ldots, \mathrm{k}) .
\end{aligned}
$$

Here, $\bar{\psi}$ represents the vector of $\mathrm{J}$ priority achievement functions. $\mathrm{P}_{\mathrm{j}}\left(\mathrm{d}^{-}\right)$is a linear function of the weighted negative deviational variables, where $\mathrm{P}_{\mathrm{j}}\left(\mathrm{d}^{-}\right)$is of the form:

$$
P_{j}\left(d^{-}\right)=\sum_{t=1}^{k} w_{j t}^{-} d_{j t}^{-}(t=1,2, \ldots, k, j \leq k)
$$

Here, $d_{j t}^{-}$is renamed for $d_{t}^{-}$to represent it at the $j$-th priority level. $w_{\overline{j t}}\left(0 \leq w_{j t} \leq 1\right)$ is the numerical weight corresponding to $\mathrm{d}_{\mathrm{jt}}^{-} \cdot \mathrm{w}_{\mathrm{jt}}^{-}$represents the weight of importance of achieving the aspired level of the t-th goal relative to the other goals, which are grouped together at the $\mathrm{j}$-th priority level. DMU may provide the numerical weight $\mathrm{w}_{\overline{\mathrm{jt}}}$ or normalized weight according to the needs, desires and practical situation of the decision-making situation. Here, $\mathrm{j}$-th priority factor $\left(\mathrm{P}_{\mathrm{j}}\right)$ is assigned to the set of commensurable goals that are grouped together in the problem formulation. In the preemptive priority $F G P, j$-th priority $P_{j}$ is preferred to the next priority $\mathrm{P}_{\mathrm{j}+1}$ regardless of any weight associated with $\mathrm{P}_{\mathrm{j}+1}$.

The priority factors have the relationships

$\mathrm{P}_{1} \gg \mathrm{P}_{2} \gg ._{. .} \mathrm{P}_{\mathrm{j}} \gg>. .>\mathrm{P}_{\mathrm{J}}$

Here, ' $>>$ ' denotes much greater than i.e. the membership goals at the first priority level $\left(\mathrm{P}_{1}\right)$ are achieved to the maximum possible before the set of membership goals at second priority level $\left(\mathrm{P}_{2}\right)$ is considered. The process will continue until the last priority level $\left(\mathrm{P}_{\mathrm{J}}\right)$ is considered.

It is to be noted that if all the fuzzy goals are considered as equally important in a decision-making context, the priority based FGP model (9) will be transformed into the weighted FGP model. It is to be noted that "too many" different priority structure can increase the computational burden to the DMU. If $\mathrm{J}$ be the total priority levels, then $\mathrm{J}$ ! priority structure may be involved there. However, in practice two to five priority levels are important to the DMU in the decision-making situation and the conflict of assigning priorities arises at the most three priority levels [2].

\section{SELECTION OF APPROPRIATE PRIORITY STRUCTURE}

In the priority based FGP approach, priorities are assigned to the goals based on the importance of achieving of the aspired levels of the goals in the decision-making situation. However, it is to be noted that in the highly conflicting decision making situation, the DMU feels confused with assigning appropriate priority structure for achievement of the aspired goals.

In order to deal with such situation, we use the concept of distance function in the proposed MOQPP. In the present FGP formulation of the MOQPP, since the aspired level of each of the membership goals is unity, the point comprising of the highest membership value of each of the goals would represent the ideal point. For different multi-objective decision making problems such as transportation problems and quality control problems, Pramanik and Roy [10-14] used distance functions for identifying best compromise solution. Let, $\mathrm{J}$ be the total number of different possible priority structure. The family of distance functions [15] is defined as follows: 
$D_{p}^{j}(w, t)=\left(\sum_{t=1}^{k} w_{t}^{p}\left(1-d_{t}^{j}\right)^{p}\right)^{1 / p}$

where $d_{t}^{j}(t=1,2, \ldots, k)$ represents the degrees of closeness of the preferred compromise solution to the optimal solution vector with respect to the t-th objective function under the $\mathrm{j}$-th priority structure. $\mathrm{w}=\left(\mathrm{w}_{1}, \mathrm{w}_{2}, \ldots, \mathrm{w}_{\mathrm{k}}\right)$ is a vector of attribute attention levels $\mathrm{w}_{\mathrm{t}}$. We assume that $\sum_{\mathrm{t}=1}^{\mathrm{k}} \mathrm{w}_{\mathrm{t}}=1$. If all the attributes are equal, then $\mathrm{w}_{\mathrm{t}}=1 / \mathrm{k}(\mathrm{t}=1,2, \ldots, \mathrm{k})$. The power $\mathrm{p}$ represents the distance parameter $1 \leqq \mathrm{p} \leqq \infty$.

For $p=2, D_{2}^{j}(w, t)=\left(\sum_{t=1}^{k} w_{t}^{2}\left(1-d_{t}^{j}\right)^{2}\right)^{1 / 2}$

For maximization problem, $\mathrm{d}_{\mathrm{t}}^{\mathrm{j}}$ is defined by $\mathrm{d}_{\mathrm{t}}^{\mathrm{j}}=$ (the preferred compromise solution)/ (the individual best solution). For minimization problem, $\mathrm{d}_{\mathrm{t}}^{\mathrm{j}}$ is defined by $\mathrm{d}_{\mathrm{t}}^{\mathrm{j}}=$ (the individual best solution)/ (the preferred compromise solution). The solution for which $\mathrm{D}_{2}^{\mathrm{j}}(\mathrm{w}, \mathrm{t})$ will be minimum, would be the most satisfying solution.

Let, $\min _{j=1,2, \ldots, J}\left\{D^{j}\right\}=D^{q}, 1 \leq q \leq J$

Then, the q-th priority structure can be identified as the appropriate priority structure for DMU.

\section{PRIORITY BASED FGP ALGORITHM TO MOQPP}

The proposed priority based FGP algorithm for solving MOQPP can be presented as follows:

Step 1: Determine the individual best solution of each objective function $\mathrm{Z}_{\mathrm{t}}(\overline{\mathrm{x}})(\mathrm{t}=1,2, \ldots, \mathrm{k})$ subject to the system constraints.

Step 2: Construct the payoff matrix as given by (3). Then we define upper tolerance limit and lower tolerance limit of each objective function of the DMU.

Step 3: Construct the membership function $\mu_{\mathrm{t}}(\overline{\mathrm{x}})(\mathrm{t}=1,2, \ldots$, k) of the objective function $\mathrm{Z}_{\mathrm{t}}(\overline{\mathrm{x}})(\mathrm{t}=1,2, \ldots, \mathrm{k})$ as given by (4).

Step 4: Find the individual best solution of the quadratic membership function $\mu_{\mathrm{t}}(\overline{\mathrm{x}})(\mathrm{t}=1,2, \ldots, \mathrm{k})$ subject to the system constraints.
Step 5: Transform the quadratic membership function $\mu_{\mathrm{t}}(\overline{\mathrm{x}})(\mathrm{t}$ $=1,2, \ldots, \mathrm{k})$ into equivalent linear membership function at $\overline{\mathrm{x}}_{\mathrm{t}}^{*}=\left(\mathrm{x}_{\mathrm{t} 1}^{*}, \mathrm{x}_{\mathrm{t} 2}^{*}, \ldots, \mathrm{x}_{\mathrm{tN}}^{*}\right)$ by first order Taylor series approximation as given by (5).

Step 5: Form the priority based FGP model as given by (9).

Step 6: Solve the problem (9) for priority based FGP model.

Step 7: Distance function as given by (13) is used to identify the appropriate priority structure.

Step 8: End.

\section{NUMERICAL EXAMPLE}

Consider the following MOQPP to illustrate the proposed priority based FGP approach:

$\max Z_{1}(x)=7 x_{1}+5 x_{2}-2 x_{1}^{2}-3 x_{2}^{2}$

$\max Z_{2}(x)=3 x_{1}+3 x_{2}-x_{1}^{2}-x_{2}^{2}$

$\max Z_{3}(x)=6 x_{1}+3 x_{2}-x_{1}^{2}-3 x_{2}^{2}$

subject to

$\mathrm{x}_{1}+\mathrm{x}_{2} \leq 3$

$4 x_{1}+x_{2} \leq 7$

$\mathrm{x}_{1} \geq 0, \mathrm{x}_{2} \geq 0$

The individual best solution subject to the system constraints is $\mathrm{Z}_{1}^{\mathrm{B}}=8.125$ at $(1.55,0.8) ; \mathrm{Z}_{2}^{\mathrm{B}}=4.485$ at $(1.382,1.47) ; \mathrm{Z}_{3}^{\mathrm{B}}=$ 7.898 at $(1.653,0.388)$.

Then the fuzzy goals appear as $Z_{1} \geq 8.125, \quad Z_{2} \geq 4.485$, $\mathrm{Z}_{3} \geq 7.898$.

Payoff matrix $=\left[\begin{array}{ccc}8.125 & 4.008 & 7.378 \\ 6.721 & 4.485 & 4.309 \\ 7.594 & 3.24 & 7.898\end{array}\right]$

Here, $\mathrm{Z}_{1}^{\mathrm{B}}=8.125, \mathrm{Z}_{1}^{\mathrm{W}}=6.721 ; \mathrm{Z}_{2}^{\mathrm{B}}=4.485, \mathrm{Z}_{2}^{\mathrm{W}}=3.24 ; \mathrm{Z}_{3}^{\mathrm{B}}=$ 7.898, $\mathrm{Z}_{3}^{\mathrm{W}}=4.309$.

The quadratic membership functions corresponding to the objective functions are as follows:

$\mu_{1}(x)=\frac{Z_{1}(x)-6.721}{8.125-6.721}=\frac{7 x_{1}+5 x_{2}-2 x_{1}^{2}-3 x_{2}^{2}-6.721}{8.125-6.721}$ 
$\mu_{2}(x)=\frac{Z_{2}(x)-3.24}{4.485-3.24}=\frac{3 x_{1}+3 x_{2}-x_{1}^{2}-x_{2}^{2}-3.24}{4.485-3.24}$,

$\mu_{3}(x)=\frac{Z_{3}(x)-4.309}{7.898-4.309}=\frac{6 x_{1}+3 x_{2}-x_{1}^{2}-3 x_{2}^{2}-4.309}{7.898-4.309}$

The quadratic membership functions $\mu_{1}(\mathrm{x}), \mu_{2}(\mathrm{x})$ and $\mu_{3}(\mathrm{x})$ are maximal at the points $(1.55,0.8),(1.382,1.47)$ and $(1.653,0.388)$ respectively subject to the system constraints.

Then, the quadratic membership functions are transformed into equivalent linear membership functions at the individual best solution point by first order Taylor polynomial series as follows:

$$
\begin{aligned}
& \hat{\mu}_{1}(\mathrm{x})=\mu_{1}(1.55,0.8)+\left(\mathrm{x}_{1}-1.55\right) \frac{\partial \mu_{1}(1.55,0.8)}{\partial \mathrm{x}_{1}}+\left(\mathrm{x}_{2}-0.8\right) \\
& \frac{\partial \mu_{1}(1.55,0.8)}{\partial \mathrm{x}_{2}} \\
& =1+\left(\mathrm{x}_{1}-1.55\right) \times 0.57+\left(\mathrm{x}_{2}-0.8\right) \times 0.142, \\
& \hat{\mu}_{2}(\mathrm{x})=\mu_{1}(1.382,1.47)+\left(\mathrm{x}_{1}-1.382\right) \frac{\partial \mu_{1}(1.382,1.47)}{\partial \mathrm{x}_{1}}+\left(\mathrm{x}_{2}-\right. \\
& 1.47) \frac{\partial \mu_{1}(1.382,1.47)}{\partial \mathrm{x}_{2}} \\
& =1+\left(\mathrm{x}_{1}-1.382\right) \times 0.19+\left(\mathrm{x}_{2}-1.47\right) \times 0.048, \\
& \hat{\mu}_{3}(\mathrm{x})=\mu_{3}(1.653,0.388)+\left(\mathrm{x}_{1}-1.653\right) \frac{\partial \mu_{3}(1.653,0.388)}{\partial \mathrm{x}_{1}}+ \\
& \left(\mathrm{x}_{2}-0.388\right) \frac{\partial \mu_{3}(1.653,0.388)}{\partial \mathrm{x}_{2}} \\
& =1+\left(\mathrm{x}_{1}-1.635\right) \times 0.751+\left(\mathrm{x}_{2}-0.388\right) \times 0.187
\end{aligned}
$$

Then priority based FGP approach for MOQPP can written as

Find $\overline{\mathrm{x}}$ so as to

$\operatorname{minimize} \bar{\psi}=$

$\left[\mathrm{P}_{1}\left(\mathrm{~d}^{-}\right), \mathrm{P}_{2}\left(\mathrm{~d}^{-}\right), \ldots, \mathrm{P}_{\mathrm{j}}\left(\mathrm{d}^{-}\right), \ldots, \mathrm{P}_{\mathrm{J}}\left(\mathrm{d}^{-}\right)\right]$ subject to

$$
\begin{aligned}
& 1+\left(\mathrm{x}_{1}-1.55\right) \times 0.57+\left(\mathrm{x}_{2}-0.8\right) \times 0.142+\mathrm{d}_{1}^{-} \geq 1 \\
& 1+\left(\mathrm{x}_{1}-1.382\right) \times 0.19+\left(\mathrm{x}_{2}-1.47\right) \times 0.048+\mathrm{d}_{2}^{-} \geq 1 \\
& 1+\left(\mathrm{x}_{1}-1.635\right) \times 0751+\left(\mathrm{x}_{2}-0.388\right) \times 0.187+\mathrm{d}_{3}^{-} \geq 1, \\
& \mathrm{x}_{1}+\mathrm{x}_{2} \leq 3 \\
& 4 \mathrm{x}_{1}+\mathrm{x}_{2} \leq 7, \\
& \mathrm{x}_{1} \geq 0, \mathrm{x}_{2} \geq 0 . \\
& \mathrm{d}_{\mathrm{t}}^{-} \geq 0(\mathrm{t}=1,2,3) .
\end{aligned}
$$

The results, obtained by different priority structure are shown in the Table 1

Note 1: All solutions of the problem are obtained by using Lingo version 6.0 .

Note 2: It is to be noted that some priority level may provide infeasible solutions. In that case, that priority level should be discarded by DMU.

Now from the Table 1, we observe that the minimum distance value is 0.041 . The results show that the priority structure under the serial $2 \& 4$ are appropriate for the DMU to get the most satisfactory solution. The optimal solution set corresponding to the appropriate priority structure is given by $\mathrm{Z}_{1}^{*}=8.125, \mathrm{Z}_{2}^{*}=$ 4.008, $\mathrm{Z}_{3}^{*}=7.378$ at $\mathrm{x}_{1}^{*}=1.55, \mathrm{x}_{2}^{*}=0.8$. The resulting membership values are $\mu_{1}(\mathrm{x})=1, \mu_{2}(\mathrm{x})=0.616, \mu_{3}(\mathrm{x})=$ 0.855 .

\section{CONCLUSIONS}

In this paper, priority based FGP approach for solving MOQPP is presented. The proposed approach is simple and easy to implement. In the proposed approach, we transform MOQPP into multi-objective linear programming problem by first order Taylor series approximation and then priority based FGP is used to solve the problem. Distance function is then applied to obtain a proper priority structure to reach the most satisfactory solution of the DMU in the decision-making context. We hope that the proposed approach can be applied to portfolio problems and other real world MOQPPs. 
Table1. Sensitivity analysis with variation of priority structure

\begin{tabular}{|l|l|l|l|l|l|}
\hline $\begin{array}{l}\text { Serial } \\
\text { No }\end{array}$ & Priority Structure & Solution Point & Objective values & Membership values & Distance values \\
\hline 1 & {$\left[\mathrm{P}^{1}\left(\mathrm{~d}_{1}^{-}+\mathrm{d}_{2}^{-}+\mathrm{d}_{3}^{-}\right)\right]$} & $1.653,0388$ & $7.594,3.24,7.9$ & $0.622,0,0.999$ & 0.095 \\
\hline 2 & {$\left[\mathrm{P}^{1}\left(\mathrm{~d}_{1}^{-}\right), \mathrm{P}^{2}\left(\mathrm{~d}_{2}^{-}\right), \mathrm{P}^{3}\left(\mathrm{~d}_{3}^{-}\right)\right]$} & $1.55,0.8$ & $8.125,4.008,7.378$ & $1,0.616,0.855$ & 0.041 \\
\hline 3 & {$\left[\mathrm{P}^{1}\left(\mathrm{~d}_{2}^{-}\right), \mathrm{P}^{2}\left(\mathrm{~d}_{1}^{-}\right), \mathrm{P}^{3}\left(\mathrm{~d}_{3}^{-}\right)\right]$} & $1.43,1.28$ & $7.405,4.447,5.46$ & $0.487,0.969,0.321$ & 0.107 \\
\hline 4 & {$\left[\mathrm{P}^{1}\left(\mathrm{~d}_{1}^{-}+\mathrm{d}_{2}^{-}\right), \mathrm{P}^{2}\left(\mathrm{~d}_{3}^{-}\right)\right]$} & $1.55,0.8$ & $8.125,4.008,7.378$ & $1,0.616,0.855$ & 0.041 \\
\hline 5 & {$\left[\mathrm{P}^{1}\left(\mathrm{~d}_{2}^{-}\right), \mathrm{P}^{2}\left(\mathrm{~d}_{1}^{-}+\mathrm{d}_{3}^{-}\right)\right]$} & $1.43,1.28$ & $7.405,4.447,5.46$ & $0.487,0.969,0.321$ & 0.107 \\
\hline
\end{tabular}

\section{ACKNOWLEDGMENTS}

The authors are very grateful to the anonymous referees for their constructive comments and suggestions, which have led to improve the quality and presentation of the paper to its current standard.

\section{REFERENCES}

[1] Ijiri, Y. 1965 Management Goals and Accounting for control. North-Holland Publication, Amsterdam.

[2] Ignizio, J. P. 1976 Goal programming and Extensions. Lexington Books, D. C. Heath and Company, London.

[3] Lee, S. M. 1972 Goal Programming for Decision Analysis. Auerbach Publishers Inc., Philadelphia.

[4] Steuer, R. E. 1986 Multiple criteria optimization: theory, computation and applications. Wiley, New York.

[5] Korhonen, P., and Yu, G. Y. 1997. A reference direction approach to multiple objective quadratic - linear programming. European Journal of Operational Research 102, 601-610.

[6] Ammar, E. E., and Khalifa, H. A. 2003. Fuzzy portfolio optimization a quadratic programming approach. Chaos Solitons Fractals 18 (5), 1045-1054.

[7] Ammar, E. E. 2008. On solutions of fuzzy random multiobjective quadratic programming with applications in portfolio problem. Information Sciences 178 (2), 468-484.

[8] Pramanik, S., and Roy, T. K. 2008. Multiobjective transportation model with fuzzy parameters: a priority based fuzzy goal programming approach. Journal of
Transportation System Engineering and Information Technology 8 (3), 40-48.

[9] Pramanik, S., and Roy, T. K. 2007. Fuzzy goal programming approach to multi-level programming problem. European Journal of Operational Research 176, $1151-1166$.

[10] Pramanik, S., and Roy, T. K. 2007. An intuitionistic fuzzy goal programming approach for a quality control problem: a case study. Tamsui Oxford Journal of Management Sciences 23 (2), 01-18.

[11] Pramanik, S., and Roy, T. K. 2007. Intuitionistic fuzzy goal programming and its application in solving multi-objective transportation problem. Tamsui Oxford Journal of Management Sciences 23 (1), 01-17.

[12] Pramanik, S., and Roy, T. K. 2006. A fuzzy goal programming technique for solving multi-objective transportation problem. Tamsui Oxford Journal of Management Sciences 22 (1), 67-89.

[13] Pramanik, S., and Roy, T. K. 2005. A fuzzy goal programming approach for multi-objective capacitated transportation problem. Tamsui Oxford Journal of Management Sciences 21 (1), 75-88.

[14] Pramanik, S., and Roy, T. K. 2005. A goal programming procedure for solving unbalanced transportation problem having multiple fuzzy goals. Tamsui Oxford Journal of Management Sciences 21 (2), 39-54.

[15] Zeleny, M. 1982 Multiple criteria decision making. McGraw-Hill, New York. 